\title{
Holistic eye-care, with ophthalmology \& optometry at the core, for developing nations, emerging economies \& the poor new initiatives!
}

\section{Opinion}

Despite great advances in Eye-Care R\&D and Applications in Advanced Countries, the vast majority of humanity that populates the developing world and emerging economies, continues to harbor huge numbers of the blind \& those heading for avoidable blindness! In fact, the poor, even in 1st world countries, endure similar distress! India (the world's fastest growing major economy in recent years) with almost $20 \%$ of the world's population inexcusably continues for decades to harbor a disproportionate $25 \%$ of the world's blind, with a significantly higher $\%$ of citizens, to boot, already with (avoidable) blindness or sprinting to it!

Blindness \& avoidable blindness continue to increase, even accelerate, instead of declining in the developing world despite all attempts so far by International, Regional, Governmental, National Eye Health Organizations like IAPB, WCO, WHO, APCO; National Ministries of Health, Eye-Care Federations, Eye-Hospitals \& a plethora of other supposedly involved/concerned bodies! Several causes can be attributed to these continuing, pathetic, deplorable $\&$ unacceptable situations failure to implement any initiative of the much-lauded global Hyderabad resolution of IAPB [Sept-2012]; failure to keep abreast of modern Eye-health curricula \& Specialties, dysfunctional National Organizations, contradictory and unhelpful resolutions of World Health \& Eye Health promotion bodies, and, above all, the very narrow focus of each national organization in Ophthalmology, Optometry, Opticianry, Eye-Care Nursing (OPD) etc. Their continuous, complacent haltering for decades within their own respective cloisters, without any significant cross -disciplinary/ Functional/Domain cooperation or engagement to educate on, promote, and deliver holistic eye-care, with urgency, compounds the folly!

A handful of renowned Eye-Hospitals/Organizations, too few and far between, like LVPEI/BLSO, SECI/SCO, Shankar Netralaya/ ESO, all in South India, have made noble, holistic efforts at redressal. They are but drops in the ocean! The national eye-care promotion \& implementation bodies in countries like India are characterized by lack of 'ownership' by their own members, resulting in internal divisiveness, factionalism \& splittism! 'elected' officials strive to perpetuate their own positions, instead of passing the baton to worthy, promising 'youngsters'. Thus goals \& targets become casualties, inevitably and rapidly! This paper \& presentation delineate, analyze these and other issues of great concern for developing nations and Emerging Economies. International cooperation within them has now become a paramount priority, without in any way diluting the importance of overall International/Regional Coordination/ Cooperation. Smaller countries, not only its neighbours, count on India for holistic support to their health-care and eye-heath needs. All the more reason for huge nations like India to set right their own EyeCare acts a priori, urgently, adopting mission-mode, project-based

\author{
Volume 6 Issue 2 - 2017
}

\author{
P Sudarshan \\ Sankara Academy of Vision, India
}

Correspondence: P Sudarshan, Founder Holistic Eye Care Ltd Ist CEO of ASCO India Ist Director of Sankara Academy of Vision, India, Email intellsouthtech@gmail.com

Received: February 03, 2017| Published: February 8, 2017

and task-force approaches, instead of the popular yet ineffectual committees!

To address these long-standing lacunae systematically, a new, inclusive, multi-disciplinary body for holistic eye-care in India, south Asia, the Middle-east, SE Asia, Africa, South America and developing countries everywhere plus emerging/transition economies, is warranted, without any dilution of cooperation, collaboration and coordination with existing national, regional \& international organizations. Such a body is being promoted by all categories of eye-health professionals, for harmonious cooperation, to effectively, jointly and collectively pre-empt, prevent $\&$ attack avoidable blindness world over. It will specially focus on the poor including the hundreds of millions in poverty even today even in the 'developed' world. Their need for modern eye-care is stark, urgent \& enormous! This new body is being constituted as a 'Sec 8' Company (a 'zero dividend' Co.) under the Indian Companies Act, by a highly representative \& promotional core team of Ophthalmologists, Optometrists, Dispensing Opticians, Eye-Care Managers, Eye-Care Nurses (OPD), Faculty, Interns, Students, Researchers, Special Educators, Administrators \& all other Eye-Care Professionals and Practitioners plus organizations Eye Hospitals, Clinics, Eye Care Companies, optical chains, Stand-Alone outlets, institutions, academia; R\&D, Eye-Health \& Professional bodies/Associations for

i. Upgradation of all Eye-Health/Care formal Education in all member-countries.

ii. Upgradation of Training (thru' CMEs, COEs, Workshops, Seminars, Training Courses, etc. in 25+ Modern Specialties \& Topics in all member countries.

iii. Conducting 12-month fellowships in $20+$ main, sub- \& Superspecialties incl. a novel 4-week internship in candidate's own city \& country.

iv. Promoting short Residencies in ALL specialties in Eye Hospitals in all main, sub \& Super specialties.

v. Faculty training work-shops \& courses in all specialties.

vi. Faculty upliftment with opportunities for $100+$ faculty/experts 
(just from India alone!) as Faculty-facilitators in CMEs/COEs/ workshops/etc.

vii. All above, with special emphasis on communication \& softskills for students, trainees \& faculty.

viii. R\&D and clinical research promotion for holistic eye-care.

ix. Project execution [with emphasis on 'hands-on' Training].

x. Fulfilment of the unanimous (global, IAPB!) Hyderabad resolution, Sept '12 CMOC \& IELOCS, degree completion [Later-al Entry'] for Diploma (D Optom) holders; accreditation, rating \& ranking of colleges; certification of optometrists.

xi. Faculty, students \& practitioners exchange programs.

xii. Future eye-care leader's identification \& Special training.

xiii. Rescue, Therapy \& Rehabilitation of innocent children with partial vision.

xiv. Support for proper recognition of optometry profession within other nations as well: Already rendered by India to Brazil, Mexico, Italy, etc.

xv. Multi farious industry engagement membership, industryspecific CMEs, COEs, Fellowships, novel 6-month Opticianry Certificate Course, etc.

xvi. Recognition of eye-care achievers \& organizations, nation-wise in South, Central, SE Asia; Africa; C\&S -America; Polynesia/
Melanesia/Micronesia and across developing nations, emerging $\&$ transition economies region-wise \& world-wide!

xvii. And, many more initiatives across the developing world, emerging economies \&, for the poor, anywhere!

To carry out and succeed in all these ambitious \& challenging tasks, the new organization will seek \& take cooperation from all quarters; will not replicate what other bodies are already doing exceptionally well; will yield \& play a supportive role to better organizations/ performers in any of \#1 to \#17 above-rather complement them and yet, carve out a unique, holistic eye-care identity in India, the developing world, emerging \&transition economies, and, above all, for the poor everywhere! Each participating nation will select its own representative in the board of the company. To start with an interim board will be constituted \& announced. Membership categories will include individuals (eye-care professionals) and organizationscorporate \& institutional.

\section{Acknowledgments}

None.

\section{Conflicts of interest}

The authors declare that there is no conflict of interest.

Funding

None. 